\title{
Folic Acid-Conjugated CuFeSe 2 Nanoparticles for Targeted T2-Weighted Magnetic Resonance Imaging and Computed Tomography of Tumors In Vivo
}

\author{
Yulan Yan ${ }^{1, *}$ \\ Chunmei Yangl,* \\ Guidong Dai ${ }^{1}$ \\ Yu Zhang' \\ Guojian Tu' \\ Yuwei $\mathrm{Li}^{2}$ \\ Lu Yang' \\ Jian Shu (D)
}

'Department of Radiology, The Affiliated Hospital of Southwest Medical University, and Nuclear Medicine and Molecular Imaging Key Laboratory of Sichuan

Province, Luzhou, Sichuan Province, People's Republic of China; ${ }^{2}$ Department of Interventional Medicine, The Affiliated Hospital of Southwest Medical University, Luzhou, Sichuan Province, People's Republic of China

*These authors contributed equally to this work
Correspondence: Lu Yang; Jian Shu Department of Radiology, The Affiliated Hospital of Southwest Medical University, and Nuclear Medicine and Molecular Imaging Key Laboratory of Sichuan Province, Luzhou, Sichuan Province, People's Republic of China Tel +86 830-2504762; +86 I8980253083 Email yangluchem@qq.com; shujiannc@I63.com
Background: Development of new long-circulating contrast agents for computed tomography (CT) and magnetic resonance imaging (MRI) of different biological systems still remains a great challenge. Here, we report the synthesis of folic acid (FA)-targeted $\mathrm{CuFeSe}_{2}$ nano-contrast agent for CT and MRI imaging in vitro and in vivo.

Methods and Results: In our study, $\mathrm{CuFeSe}_{2}$ was fabricated through a facile and green aqueous reaction and then further aminated through silanization. The amine-functionalized $\mathrm{CuFeSe}_{2}-\mathrm{NH}_{2}$ nanoparticles enable the covalent conjugation of folate-conjugated polyethylene glycol (FA-PEG-COOH) as a targeting ligand onto their surface, which could improve the dispersion and endue the targetability of nanoparticles, respectively. The formed multifunctional $\mathrm{CuFeSe}_{2}$-PEG-FA nanoparticles were characterized via different techniques, which exhibited outstanding dispersion, good biocompatibility and excellent FA-targeted capability. Meanwhile, the nanoparticles were quite safe in the given concentration range as confirmed by in vitro and in vivo toxicity assay. Importantly, $\mathrm{CuFeSe}_{2}$-PEG-FA nanoparticles were successfully applied in CT/MRI dual-modality imaging in vitro and in vivo, which showed a better imaging performance and targeted capability.

Conclusion: Therefore, the constructed $\mathrm{CuFeSe}_{2}$-PEG-FA nanoparticles have a great potential as an efficient contrast agent for dual-modality imaging of different biological systems. Keywords: $\mathrm{CuFeSe}_{2}$ nanoparticles, magnetic resonance imaging, computed tomography imaging, dual-modality imaging, folic acid

\section{Introduction}

Computed tomography (CT) is one of the most widely used imaging techniques in diagnostic medicine due to its high resolution, unlimited tissue penetration and cost effectiveness. $^{1,2}$ The follow-up emerging magnetic resonance imaging (MRI) has also been identified as a powerful and noninvasive imaging technique because of its no ionizing radiation and high-quality soft tissue contrast. ${ }^{3,4}$ However, use of a large amount of contrast agents is often required for accurate diagnosis of various diseases because non-contrast techniques have lower sensitivity and the use of the contrast agents can help to clarify images and allow better interpretation. ${ }^{5,6}$ It is well-known that multimodal imaging can integrate the advantages of different imaging modalities by overcoming their individual limitations. ${ }^{7,8} \mathrm{CT}$ imaging is very suitable for bone and calcification imaging and MRI can offset the poor soft- 
tissue contrast of $\mathrm{CT}$, so that this CT/MRI dual-modality imaging is of significance to the clinical complementation and beneficial for improving the diagnostic efficiency of diseases. ${ }^{9}$ More importantly, the future of CT/MRI will greatly benefit from the development of CT/MRI dualmodality contrast agents.

Currently, clinically used control agents, eg small molecular iodinated contrast agents and gadolinium compounds, are some single-modality control agents for CT or MRI imaging, which suffer from lower sensitivity, potential allergy and renal toxicity. ${ }^{10,11}$ Compared with the above conventional contrast agents, nanoparticles refer to a class of materials with a one-dimensional space size $<100 \mathrm{~nm}$, which have special volume and structure. In addition, nanomaterials are not easily degraded by various enzymes and have advantages of low toxicity, high signal intensity, excellent targeting capability, long half-life, good surface activity and strong surface modification. ${ }^{12}$ This indicates that nano-contrast agents have a great potential for molecular imaging. To date, some contrast agents have been fabricated for CT/MRI dual-modality imaging, including FeBi NPs, Gd chelated Au NPs, FePt NPs, Au or TaOx decorated $\mathrm{Fe}_{3} \mathrm{O}_{4} \mathrm{NPs}$, and $\mathrm{NaHoF}_{4}$ NPs. ${ }^{9,13-19}$ These nanoparticles have displayed inspiring performance and may be used as some promising contrast agents for CT/MRI dual-modality imaging of different biological systems.

$\mathrm{CuFeSe}_{2}$, a ternary sulfide nanomaterial, has high photothermal conversion efficiency (82\%), superparamagnetic properties and effective X-ray attenuation, which makes for ideal nanoprobes for multimodal imaging and tumor photothermal therapy. ${ }^{3}$ It's reported that some nanoparticles based on $\mathrm{CuFeSe}_{2}$ have been developed for modality imaging and photothermal therapy, eg $\mathrm{CuFeSe}_{2}$ @PTMP-PMAA nanocrystals, CFS@DOX, MPEGPCL@CuFeSe $\mathrm{Cu}_{2}$ and bioactive glass scaffolds functionalized by the $\mathrm{CuFeSe}_{2}$ nanocrystals. ${ }^{3,20-22}$ Furthermore, we have been engaged in the development of multimodal contrast agents based on $\mathrm{CuFeSe}_{2}$ in recent years and successfully fabricated the nanoparticles based on $\mathrm{CuFeSe}_{2}$ for modality imaging. ${ }^{21,23}$ However, the attention about molecular research based on $\mathrm{CuFeSe}_{2}$ was not as much as we thought in the field of multimodal imaging due to complex synthetic processes, unstable performance and non-definite targetability. ${ }^{3,22}$ Therefore, there is currently still a need for developing $\mathrm{CuFeSe}_{2}$-based modality contrast agents with great clinical translation potential.
Of course, an outstanding contrast agent should not only have excellent imaging performance but also own good targeting capability. For the targeted tumor imaging, it is necessary to modify nanoparticles with specific ligands that can recognize molecular signatures on the surface of cancer cells. As one of the most studied cancertargeting ligands, folic acid (FA) has been known to target FA receptors (FAR) that are overexpressed in some malignant tumors including brain, head and neck, lung, breast, ovary, endometrium, kidney, and myeloid cancers. ${ }^{24-26}$ In contrast, the expression of FAR on normal tissue cell is more conservative. Therefore, the overexpression of FAR provides a theoretical basis for targeted therapy and imaging of some specific tumors. Up to now, some nanomaterials based on FA have been fabricated as potential control agents for targeted imaging and therapy of some tumors. ${ }^{27-29}$

Inspired by the property of $\mathrm{CuFeSe}_{2}$ and the target ability of FA, in our study, novel types of $\mathrm{CuFeSe}_{2}$-PEGFA nanoparticles were synthesized and explored as dualmodality contrast agents for CT and MRI. A series of evaluations were carried out to characterize their morphology, size, biocompatibility, toxicity and targetability. Furthermore, the developed $\mathrm{CuFeSe}_{2}$-PEG-FA nanoparticles were used as a nanoprobe for CT/MRI dual-modality imaging in vitro (4T1 and HepG2 cells) and in vivo (4T1 tumor model).

\section{Materials and Methods \\ Chemicals and Materials}

Selenium powder ( $\mathrm{Se}, \geq 99.5 \%$, $\mathrm{WM}=78.96$ ), sodium borohydride $\left(\mathrm{NaBH}_{4}, \geq 99.0 \%, \mathrm{WM}=37.83\right), \mathrm{CuCl}_{2} \cdot 2 \mathrm{H}_{2}$ $\mathrm{O}(\geq 99.0 \%, \mathrm{WM}=170.48), \mathrm{FeSO}_{4} \cdot 7 \mathrm{H}_{2} \mathrm{O}(\geq 99.0 \%, \mathrm{WM}=$ 278.01), 3-aminopropyltriethoxysilan (APTES, $\geq 98 \%$, WM = 221.37), dimethylformamide (DMF), folic acid (FA, $\geq 98 \%, \mathrm{WM}=441.4), \mathrm{NH}_{2}$-PEG-COOH $(\mathrm{MW}=2000$ ), $\mathrm{N}$-(3-dimethylaminopropyl)-N'-ethylcarbodiimide hydrochloride $\quad(E D C, \geq 98 \%, \quad M W=191.7)$, N-hydroxysuccinimide (NHS, $\geq 98 \%, W M=115.09$ ) and chloral hydrate were purchased from Shanghai Macklin Biochemical Co., Ltd. Roswell Park Memorial Institute1640 (RPMI-1640) medium, Dulbecco's minimum essential medium (DMEM) high sugar medium and fetal bovine serum (FBS) were purchased from Sigma-Aldrich. Penicillin-streptomycin solution, trypsin digestion fluid and PBS buffer (pH 7.2-7.4) were purchased from Beyotime. 


\section{Synthesis of $\mathrm{CuFeSe} 2-\mathrm{NH}_{2}, \mathrm{CuFeSe}_{2}$ -PEG-FA}

The magnetic $\mathrm{CuFeSe}_{2}$ nanoparticles were prepared according to a previously reported method. ${ }^{3} 39.48 \mathrm{mg}$ of Se powder and $50 \mathrm{mg}$ of $\mathrm{NaBH}_{4}$ were dispersed in $100 \mathrm{~mL}$ of ultrapure water and stirred at room temperature at ambient conditions with the protection of argon flow. After the Se powder was completely dissolved, a $5 \mathrm{~mL}$ mixture of $\mathrm{CuCl}_{2}$ $\cdot 2 \mathrm{H}_{2} \mathrm{O}(42.62 \mathrm{mg})$ and $\mathrm{FeSO}_{4} \cdot 7 \mathrm{H}_{2} \mathrm{O}(69.75 \mathrm{mg})$ was added. The mixture was stirred at room temperature for $2 \mathrm{~h}$. The nanocrystals were separated by centrifugation, dried under reduced pressure and stored at $0-4{ }^{\circ} \mathrm{C}$. $\mathrm{CuFeSe}{ }_{2}-\mathrm{NH}_{2}$ nanoparticles were obtained by adding $40 \mu \mathrm{L}$ of APTES to a suspension of $10 \mathrm{mg} \mathrm{CuFeSe}$ in $2 \mathrm{~mL}$ DMF. The mixture was sonicated for the first 2 minutes and kept under energetic stirring for $6 \mathrm{~h}$ at room temperature. The nanoparticles were washed from the unreacted APTES by three centrifugation and redispersion steps in DMF.

Next, folate-conjugated polyethylene glycol (FA-PEG$\mathrm{COOH}$ ) was fabricated on the basis of the method in a previous study. ${ }^{30}$ To modify the $\mathrm{CuFeSe} 2-\mathrm{NH}_{2}$ nanoparticles with FA-PEG-COOH, $5.4 \mu \mathrm{mol}$ FA-PEG-COOH (12.39 mg), $27 \mu \mathrm{mol}$ EDC (5.18 mg) and $27 \mu \mathrm{mol}$ NHS $(3.11 \mathrm{mg}$ ) were dissolved in $2 \mathrm{~mL}$ DMSO respectively. The three solutions were mixed and stirred for $2 \mathrm{~h}$ to activate the carboxyl groups of FA-PEG-COOH. Then $20 \mathrm{mg} \mathrm{CuFeSe}{ }_{2}-\mathrm{NH}_{2}$ nanoparticles dissolved in DMF $(10 \mathrm{~mL})$ were added to the activated FA-PEG-COOH solution, and the mixture was stirred mildly for $3 \mathrm{~h}$ at room temperature in the dark. To ensure a maximum PEG density, the last functionalization step was achieved overnight, under vigorous stirring at $60{ }^{\circ} \mathrm{C}$. The $\mathrm{CuFeSe}_{2}-$ PEG-FA nanoparticles were precipitated by centrifugation $(10,000 \mathrm{rpm} / \mathrm{min}, 10 \mathrm{~min})$, and purified with ethanol through several cycles of redispersion and centrifugation. The synthesis process is shown in Figure 1.

\section{Characterization}

JEM 1200EX transmission electron microscope (TEM, FEI, USA) was used to detect the morphology and energy spectrum of three nanoparticles, including $\mathrm{CuFeSe}{ }_{2}, \mathrm{CuFeSe}_{2}-\mathrm{NH}_{2}$ and $\mathrm{CuFeSe}_{2}$-PEG-FA. The elemental composition of $\mathrm{CuFeSe}_{2}$ and $\mathrm{CuFeSe}_{2}$-PEG-FA was analyzed respectively by X-ray powder diffractometer (XRD, Bruker, Germany). The scanning conditions were as follows: $2 \theta$ range $10-90^{\circ}$, scanning rate $6 \% \mathrm{~min}$, and scanning step length 0.02 . Various elemental contents of $\mathrm{CuFeSe}_{2}$-PEG-FA were detected using inductively coupled plasma optical emission spectrometry (ICP-OES, Agilent, USA). Test conditions were as follows: emission power $1.0 \mathrm{~kW}$, plasma gas flow $15 \mathrm{~L} / \mathrm{min}$, auxiliary gas flow $1.5 \mathrm{~L} / \mathrm{min}$, argon carrier, detection mode for axial observation, linear calibration. Different chemical bonds in $\mathrm{CuFeSe}{ }_{2}-\mathrm{NH}_{2}$, and $\mathrm{CuFeSe}_{2}$-PEG-FA nanoparticles were explored by Fourier transform infrared spectrometer (FTIR, Shimadzu, Japan). The absorbance of $\mathrm{CuFeSe}_{2}$-PEG-FA nanoparticles solution was measured with a SHIMADZU UV-2600 spectrophotometer.

In vitro $\mathrm{CT}$ and MRI of $\mathrm{CuFeSe}_{2}$-PEG-FA samples were performed on IQon CT (Philips, Holland) and 3.0 T MRI (Siemens, German) respectively. As a control, in vitro $\mathrm{CT}$ imaging of iohexol (Yangzijiang Pharmaceutical Group Limited) at the corresponding concentration was also carried out. The scanning parameters of CT were as follows: tube voltage $120 \mathrm{kV}$, tube current $100 \mathrm{mAs}$, matrix $512 \times 512$, slice thickness $0.8 \mathrm{~mm}$, and field of view (FOV) $150 \mathrm{~mm}$. The parameters of MRI were as follows: repetition time (TR) $5290 \mathrm{~ms}$, echo time (TE) $68 \mathrm{~ms}$, matrix $256 \times 256$, slice thickness $1 \mathrm{~mm}$, field of view $180 \mathrm{~mm}$, number of excitations 2 .

\section{Cell Culture and Cytotoxicity Assessment}

4T1 (murine breast cancer cells) and HepG2 cells were obtained from ATCC. Two cells were cultured in RPMI-

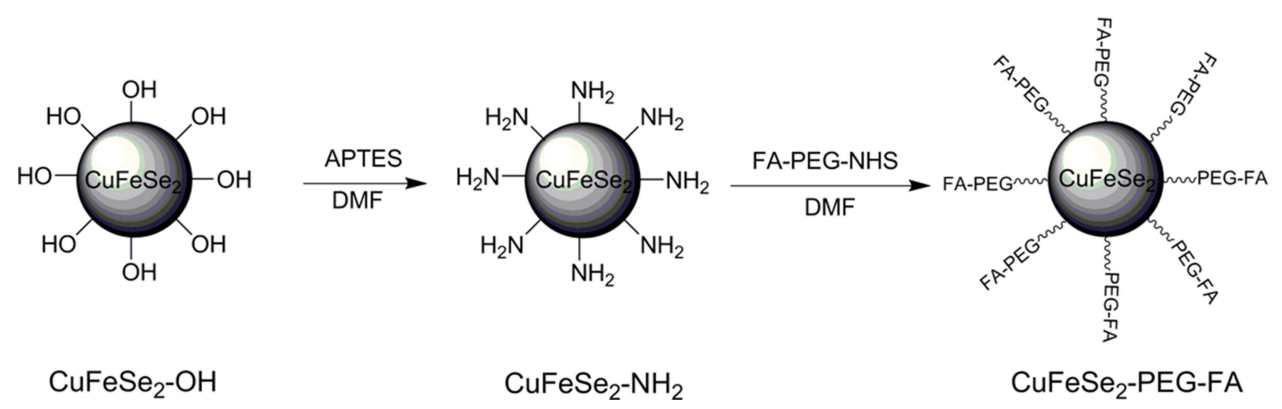

Figure I Schematic representation of the synthesis of multifunctional CuFeSe 2 -PEG-FA nanoparticles. 
1640 and DMEM respectively supplemented with $10 \%$ FBS in a cell incubator at $37{ }^{\circ} \mathrm{C}$ and $5 \% \mathrm{CO}_{2}$ conditions. The cell cytotoxicity in vitro was measured by 3-(4,5-dimethylthiazol-2-yl)-2,5-diphenyltetrazolium bromide (MTT) assay. 4T1 and HepG2 cells were seeded into a 96-well cell culture plate at 5000/well and then incubated for $24 \mathrm{~h}$ at $37{ }^{\circ} \mathrm{C}$ and $5 \% \mathrm{CO}_{2}$. RPMI-1640 solutions of $\mathrm{CuFeSe}_{2}$-PEG-FA nanoparticles with different sizes (concentrations: $200 \mu \mathrm{g} / \mathrm{mL}, 100 \mu \mathrm{g} / \mathrm{mL}, 50 \mu \mathrm{g} / \mathrm{mL}$, $25 \mu \mathrm{g} / \mathrm{mL}, 12.5 \mu \mathrm{g} / \mathrm{mL}$ and $6.25 \mu \mathrm{g} / \mathrm{mL}$ ) were added to the wells. 4T1 and HepG2 cells were then incubated for 24 $\mathrm{h}$ at $37{ }^{\circ} \mathrm{C}$ and $5 \% \mathrm{CO}_{2}$, and the cell viability was calculated using a typical MTT assay.

\section{In Vitro Targeted Assessment}

$4 \mathrm{~T} 1$ and HepG2 cells $\left(1 \times 10^{4} / \mathrm{mL}\right)$ were seeded into a 6 -well cell culture plate at $2 \mathrm{~mL} /$ well and then incubated overnight at $37{ }^{\circ} \mathrm{C}$ and $5 \% \mathrm{CO}_{2}$. And then, DMEM solution of $\mathrm{CuFeSe}_{2}$-PEG-FA and $\mathrm{CuFeSe}_{2}$ nanoparticles was added to the wells $(2 \mathrm{~mL} / \mathrm{well}, 100 \mu \mathrm{g} / \mathrm{mL})$ respectively. As a control, the DMEM solution was added to the corresponding wells and incubated for 6 hours. Next, the cells were washed 5 times with PBS. Finally, the binding condition of the cells and $\mathrm{CuFeSe}_{2}$-PEG-FA/CuFeSe $e_{2}$ nanoparticles was evaluated by the inverted fiber mirror (the magnification was $\times 400$ ).

Furthermore, the related tests were further conducted to verify the successful modification of FA. Briefly, 4T1 cells were seeded in a 6-well plate with a density of $2 \times 10^{4}$ cells per well, and a blocking assay was carried out using two groups of cells. One group (A group) was treated with different concentrations of $\mathrm{CuFeSe}_{2}$-PEG-FA $(0,50,100$, and $200 \mathrm{ug} / \mathrm{mL}$ ). The other group (B group) was first treated with FA (300 ug/mL, $1.5 \mathrm{~mL}, \mathrm{DMEM})$ for $4 \mathrm{~h}$, and then, different concentrations of $\mathrm{CuFeSe}_{2}$-PEG-FA ( 0 , 50, 100, and $200 \mathrm{ug} / \mathrm{mL}$ ) dispersion were added. After incubation for $4 \mathrm{~h}$, each group of cells was washed with PBS five times. Finally, the in vitro CT and MR imaging were performed.

\section{Toxicity Assessment In Vivo}

To investigate the in vivo toxicity, $\mathrm{CuFeSe}_{2}$-PEG-FA nanoparticles $(0.58 \mathrm{mmol} \mathrm{Fe} / \mathrm{kg})$ were intravenously injected through the tail vein of $\mathrm{BABL} / \mathrm{C}$ female mice. Then, the mice $(\mathrm{n}=15)$ were sacrificed at different time points post-injection $(1,3,5,10$, and $15 \mathrm{~d}$, respectively). For comparison, mice $(n=3)$ injected with glucose solution were used as controls and sacrificed at $15 \mathrm{~d}$. The major organs (heart, liver, spleen, lung, kidney, and muscle of left thigh) were carefully harvested, weighed, and fixed with $4 \%$ formalin solution. Finally, pathological section and hematoxylin and eosin (H\&E) staining analysis were carried out to assess the in vivo toxicity of the $\mathrm{CuFeSe}_{2}$ PEG-FA nanoparticles.

\section{CT/MRI Dual-Modality Imaging of Cancer Cells In Vitro}

The suspension of $4 \mathrm{~T} 1$ and HepG2 cells $\left(1 \times 10^{4} / \mathrm{mL}\right.$, $3 \mathrm{~mL}$ ) were seeded in T25 culture bottles respectively and incubated at $37{ }^{\circ} \mathrm{C}$ and $5 \% \mathrm{CO}_{2}$. After overnight culture to bring the cells to adhesion, the cells were washed 2 times with PBS. Subsequently, $4 \mathrm{~mL}$ of $\mathrm{CuFeSe}_{2}$-PEG-FA solution (DMEM medium preparation, $200 \mu \mathrm{g} / \mathrm{mL}$ ) was added to T25 the culture bottle and incubated for 6 hours. As a control, $4 \mathrm{~mL}$ of $\mathrm{CuFeSe}_{2}$ $(200 \mu \mathrm{g} / \mathrm{mL}$ ) and DMEM solution was added to the corresponding T25 culture bottles respectively. After that, the cells were washed 5 times with PBS and digested for 2 minutes using trypsin digestion fluid. Finally, centrifugal separation was carried out (1000 rpm/min, $2 \mathrm{~min})$ and heavy suspension was performed with $1 \mathrm{~mL}$ PBS.

CT imaging of these cell suspensions was performed using IQon CT (Philips, Holland, tube voltage $=120 \mathrm{kV}$, tube current $=100 \mathrm{mAs}$, matrix $=512 \times 512$, slice thickness $=$ $0.8 \mathrm{~mm}$, field of view $=150 \mathrm{~mm}$ ). $\mathrm{CT}$ values and effective atomic numbers were measured by the corresponding reprocessing workstation. For MRI, a Siemens Prisma 3.0 T Signa HDxt superconductor clinical MR system (Siemens, German) was used. T2 weighted imaging (T2WI) was obtained with $1 \mathrm{~mm}$ slice thickness, 5290/68 ms TR/TE, $180 \mathrm{~mm}$ FOV, 256×256 matrix and 2 NEXs.

\section{CT/MRI Dual-Modality Imaging In Vivo}

All procedures and animal experiments were approved by the Animal Ethical Committee of Southwest Medical University (2020423) and conducted in accordance with state regulations. Animal care and handling procedures were in agreement with the guidelines of the Regional Ethics Committee for Animal Experiments. The 6- to 8-week-old BABL/C female mice (average body weight: 20 g, Dashuo Animal Technology Limited, Jianyang) were subcutaneously injected with $1 \times 10^{6} 4 \mathrm{~T} 1$ cells in $0.2 \mathrm{~mL}$ PBS solution on the right leg root. While the tumor nodules reached a volume of $100 \mathrm{~mm}^{3}$, the mice were anesthetized by intraperitoneal injection of $5 \%$ chloral 
hydrate and $0.1 \mathrm{~mL}$ glucose solution of $\mathrm{CuFeSe}_{2}$-PEG-FA nanoparticles $(0.58 \mathrm{mmol} \mathrm{Fe} / \mathrm{kg})$ was delivered into the mice via the tail vein. As a control, $0.1 \mathrm{~mL} \mathrm{CuFeSe}{ }_{2}$ solution and $0.1 \mathrm{~mL}$ glucose solution $(5 \%)$ were intravenously injected via the tail vein.

For MRI, 3.0T Prisma MR (Siemens, German) was used to scan the mice with a wrist coil. For each animal, T2WI and T2*map were obtained both before and after administration of the $\mathrm{CuFeSe}_{2}$-PEG-FA, $\mathrm{CuFeSe}_{2}$ nanoparticles and $5 \%$ glucose solution respectively at the time points of $2 \mathrm{~min}, 30 \mathrm{~min}, 1,1.5,2,3,4,5,6,8$, and 12 h post-injection (T2WI: TR $=5290 \mathrm{~ms}, \mathrm{TE}=70 \mathrm{~ms}$, slice thickness $=2 \mathrm{~mm}$, matrix $=256 \times 256, \mathrm{FOV}=120 \mathrm{~mm}$; T2*map: TR $=293.0 \mathrm{~ms}, \mathrm{TE}=2.98 \mathrm{~ms}$, slice thickness $=$ $2 \mathrm{~mm}$, matrix $=256 \times 256, \mathrm{FOV}=120 \mathrm{~mm}$, flip angle $=$ $60^{\circ}$ ). After the scanning, the section showing the maximum size of the tumor was selected in T2WI and T2*map for further image fusion and regions of interest (ROIs) were delineated to measure $\mathrm{T} 2 *$ values of the tumor using the MRI postprocessing workstation. The above tumor-bearing $\mathrm{BALB} / \mathrm{C}$ mice were sacrificed after $\mathrm{MR}$ scanning at the $12 \mathrm{~h}$ time point. And then, the tumor tissues were carefully harvested and fixed with $4 \%$ formalin solution. Next, ICP was used to detect $\mathrm{Fe}$ element content in tumor tissues.

Further in vivo tumor $\mathrm{CT}$ imaging was conducted before and after the intravenous injection of $0.1 \mathrm{~mL}$ glucose solution of $\mathrm{CuFeSe}_{2}$-PEG-FA nanoparticles (dose $=100 \mathrm{mg}$ / $\mathrm{kg}$ ). The section showing the maximum size of the tumor was selected and the ROI of the tumor was delineated to measure average CT value and effective atomic number. The scanning parameters of CT were as follows: tube voltage $120 \mathrm{kV}$, tube current $60 \mathrm{mAs}$, matrix $512 \times 512$, slice thickness $0.8 \mathrm{~mm}$.

\section{Data Analysis}

Continuous variables (T2* values, $\mathrm{CT}$ values, and $\mathrm{Fe}$ element content in tumor tissues) were expressed as mean \pm standard deviation (SD) because the distribution of data was normal. $\mathrm{T} 2 *$ values and $\mathrm{CT}$ values before and after injection of the $\mathrm{CuFeSe}_{2}$-PEG-FA nanoparticles were compared using paired sample $t$-test. Group design $t$-test was used to compare the $\mathrm{Fe}$ contents of tumor tissue in the experimental and control group. All statistical analyses were conducted using SPSS 25. A two-sided $p$ value $<$ 0.05 was considered significant.

\section{Results and Discussion Characterization of $\mathrm{CuFeSe}_{2}-\mathrm{PEG}-\mathrm{FA}$}

The resultant nanoparticles were characterized with TEM to determine their morphology and size. Small spherical particles of $\mathrm{CuFeSe}_{2}$ are clearly observed (Figure 2A). The crystal structure of the nanoparticles was revealed by their high-resolution TEM (HRTEM) image (Figure 2B) and the continuous selected area electron diffraction (SAED) rings in the inset (Figure 2C). TEM was also used to characterize the morphology and size distribution of the formed $\mathrm{CuFeSe}_{2}-\mathrm{NH}_{2}$ and $\mathrm{CuFeSe}_{2}$-PEG-FA nanoparticles (Figure 2D and E). It's clear that both nanoparticles possessed a spherical shape and a uniform size distribution with a mean diameter of $9.80 \mathrm{~nm}$ for $\mathrm{CuFeSe} \mathrm{SH}_{2}-\mathrm{NH}_{2}$ nanoparticles (Figure 2F) and $10.89 \mathrm{~nm}$ for $\mathrm{CuFeSe}_{2}$-PEG-FA nanoparticles (Figure 2G), respectively. By comparison with the pristine $\mathrm{CuFeSe}_{2}$ nanoparticles that have a size of $5.10 \mathrm{~nm}$ (Figure S1), the increased diameter of the nanoparticles should be associated with the APTES modification onto the particle surfaces.

The ratio of $\mathrm{Cu} / \mathrm{Fe} / \mathrm{Se}$ in $\mathrm{CuFeSe}_{2}$-PEG-FA nanoparticles was 1:1:2, measured by ICP-OES. Meanwhile, energy dispersive X-ray spectroscopy (EDX) was performed to identify the composition and verify the presence of the three elements $(\mathrm{Cu}, \mathrm{Fe}$, and $\mathrm{Se})$ in each individual nanocrystal. In supporting information (Figure S2) the EDX spectrum showed that the three elements of $\mathrm{Cu}, \mathrm{Fe}$, and $\mathrm{Se}$ were coexistent in the synthesized nanoparticles.

The crystal structures of $\mathrm{CuFeSe}_{2}$ and $\mathrm{CuFeSe}_{2}$-PEG-FA nanocrystals were further characterized by XRD. The XRD pattern confirmed the existence of $\mathrm{CuFeSe}_{2}$, and a broad peak from $22^{\circ}$ to $28^{\circ}$ should be attributed to the amorphous silica. This indicated that silica was successfully coated onto the $\mathrm{CuFeSe}_{2}$ nanoparticles surfaces (Figure 3A). Further investigation with the FTIR spectra confirmed the presence of the silica shell (Figure 3B). The sample exhibited a strong broad band at around $\mathrm{v}=1101 \mathrm{~cm}^{-1}$, corresponding to the $\mathrm{Si}-\mathrm{O}-\mathrm{Si}$ asymmetric $\left(\mathrm{v}_{\mathrm{as}}\right)$ stretching vibration. TEM images of the core-shell structured $\mathrm{CuFeSe} \mathrm{S}_{2}-\mathrm{NH}_{2}$ nanocomposites showed that the mean diameter of the particles was $9.80 \mathrm{~nm}$ and the thickness of the silica shell was $4.70 \mathrm{~nm}$. Stability test showed that $\mathrm{CuFeSe}_{2}$-PEG-FA nanoparticles possessed excellent solubility and stability in different media, such as $\mathrm{H}_{2} \mathrm{O}$, phosphate-buffered saline (PBS), $0.9 \%$ saline $(\mathrm{NaCl})$, and $5 \%$ glucose solution, as demonstrated by their similar absorbance (Figure S3A). Their excellent colloidal stability was further demonstrated by the absence of precipitates or 

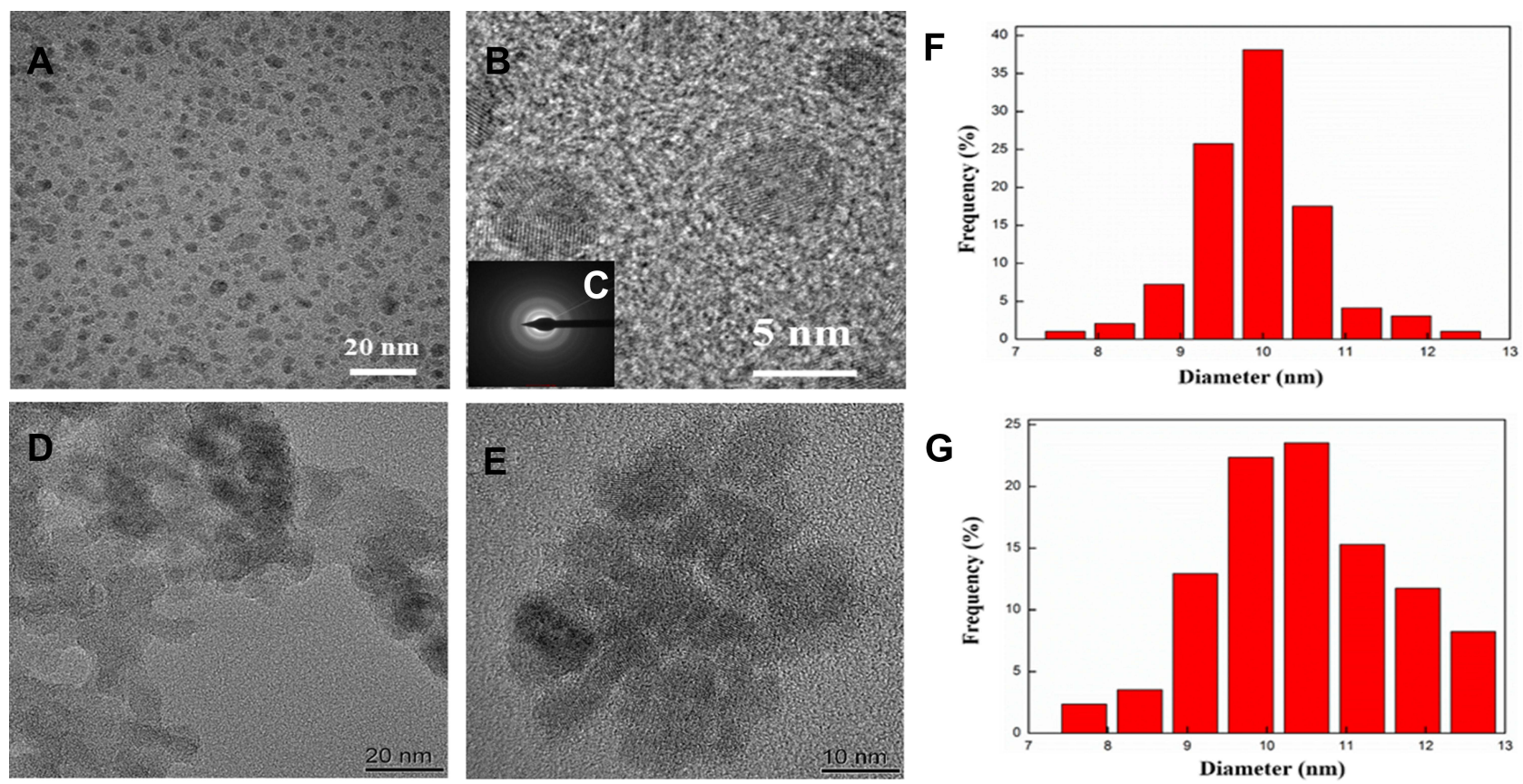

Figure 2 (A) TEM image of CuFeSe $e_{2}$ nanoparticles. (B) High-resolution TEM image and (C) SAED pattern of CuFeSe ${ }_{2}$ nanoparticles. (D) TEM image of CuFeSe $\mathrm{THH}_{2}$ nanocomposite. (E) TEM image of CuFeSe 2 -PEG-FA nanocomposites. (F) The size distribution histograms of $\mathrm{CuFeSe}_{2}-\mathrm{NH}_{2}$. (G) The size distribution histograms of CuFeSe $e_{2}$ -PEG-FA.
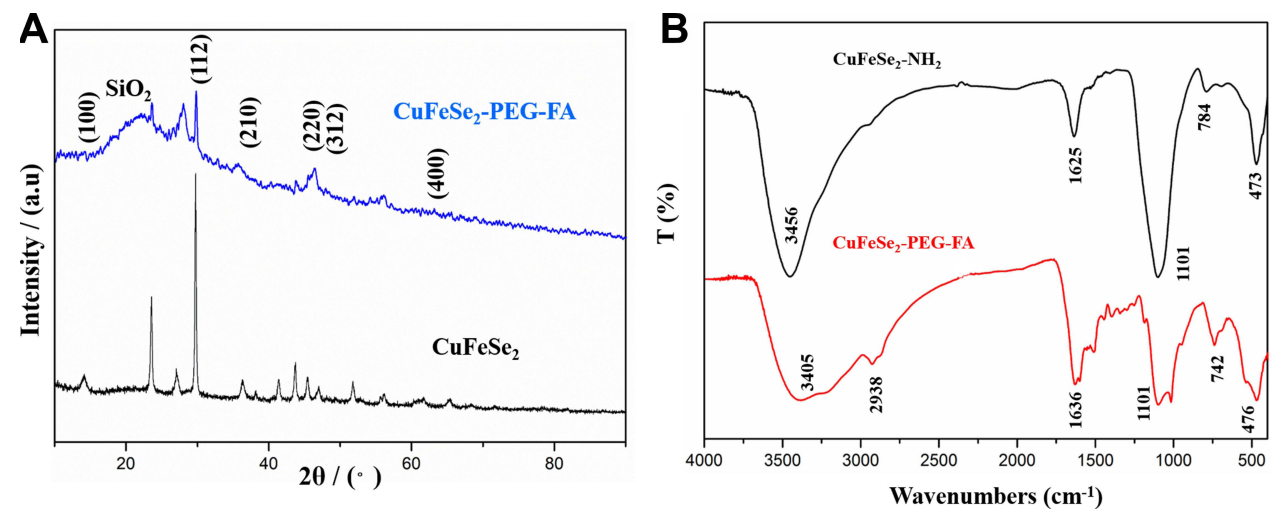

Figure 3 (A) X-ray diffraction pattern of $\mathrm{CuFeSe}_{2}$ and CuFeSe 2 -PEG-FA. (B) FTIR spectra of CuFeSe ${ }_{2}-\mathrm{NH}_{2}$, and CuFeSe 2 -PEG-FA.

aggregates in their aqueous solutions during 15 days of storage (Figure S3B).

It's important to characterize the $\mathrm{X}$-ray attenuation and magnetic properties of the $\mathrm{CuFeSe}_{2}$-PEG-FA nanoparticles before their use as a dual-modality contrast agent for CT and MRI. Figure 4A showed that the effective atomic number of the targeted $\mathrm{CuFeSe}_{2}$-PEG-FA nanocrystals and iohexol increased with the rise of the concentrations. Although the increase of the $\mathrm{CuFeSe}_{2}$-PEG-FA nanocrystals was inferior to that of iohexol, the effective atomic number of these nanocrystals still displayed a linear upward trend (Figure 4B), which indicated that the
$\mathrm{CuFeSe}_{2}$-PEG-FA nanoparticles had a great potential for enhanced CT imaging. Meanwhile, we also measured CT values of the targeted $\mathrm{CuFeSe}_{2}$-PEG-FA nanoparticles, discovering that there still existed a linear upward trend between $\mathrm{CT}$ value and the $\mathrm{CuFeSe}_{2}$-PEG-FA nanoparticles concentration (Figure S5). Furthermore, for the in vitro MRI imaging, it could be seen that the signal intensity of T2WI decreased with the increase of the concentration of the $\mathrm{CuFeSe}_{2}$-PEG-FA nanoparticles (Figure 4C). Its transverse relaxation rate $\left(r_{2}\right)$ was calculated to be 4.28 $\mathrm{mM}^{-1} \mathrm{~S}^{-1}$ (Figure 4D). Therefore, these in vitro imaging results demonstrated the robustness of $\mathrm{CuFeSe}_{2}$-PEG-FA 

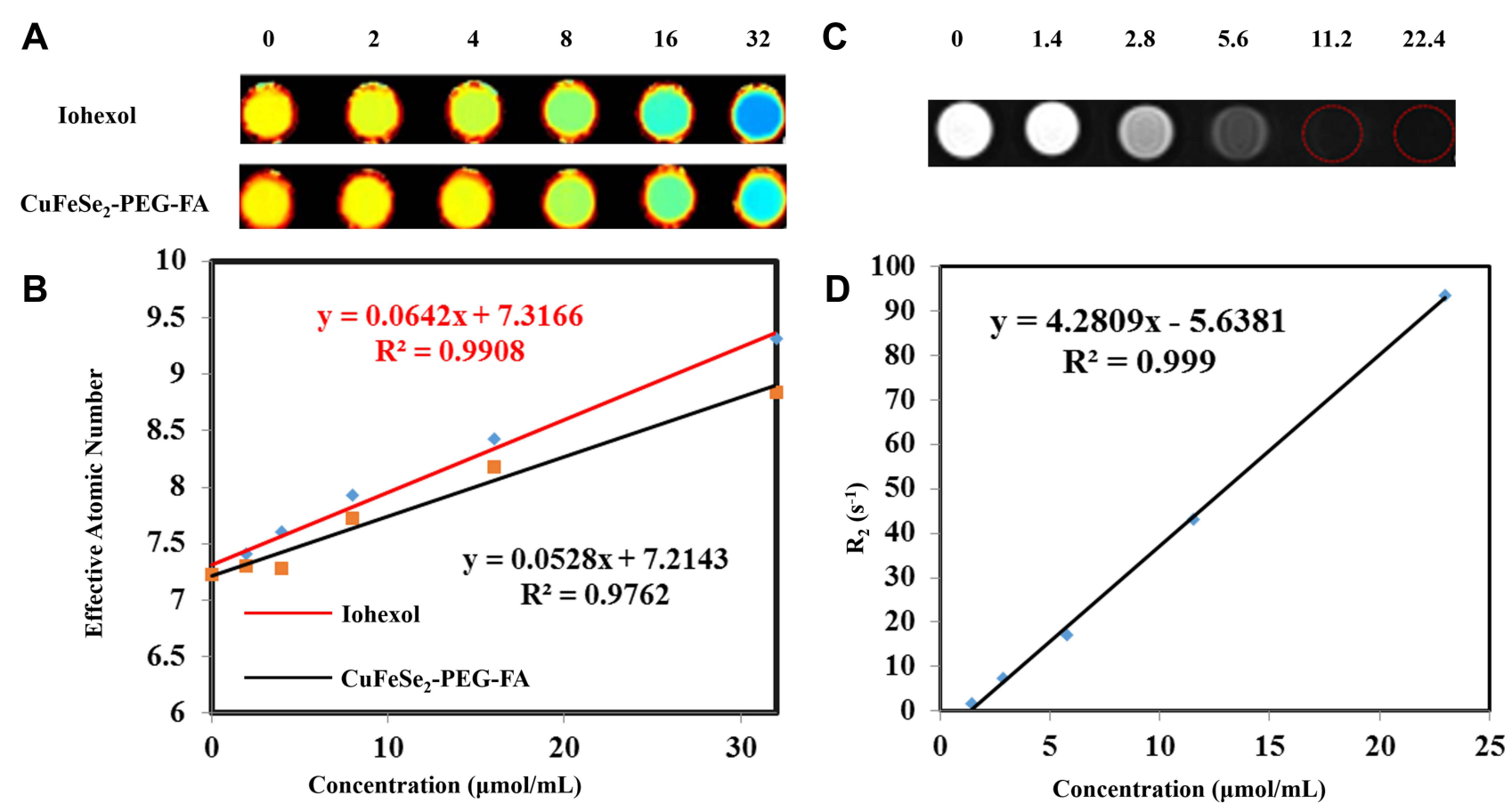

Figure 4 (A) In vitro CT imaging of iohexol and the CuFeSe - PEG-FA nanocrystals with the different concentration. (B) The linear correlation between the effective atomic number of iohexol and CuFeSe 2 -PEG-FA nanocrystals with their concentrations respectively. (C) In vitro MRI imaging of CuFeSe 2 -PEG-FA nanoparticles using different concentrations. (D) The transverse relaxation rate $\left(r_{2}\right)$ was determined to be $4.28 \mathrm{mM}^{-1} \mathrm{~S}^{-1}$.

nanoparticles as a contrast agent for in vivo dual-modality imaging if they were safe and had good biocompatibility.

\section{Cell Culture and Cytotoxicity \\ Assessment}

After incubation of 4T1 and HepG2 cells with $\mathrm{CuFeSe}_{2}-$ PEG-FA at the particle concentration of 200, 100, 50, 25, 12.5 and $6.25 \mu \mathrm{g} / \mathrm{mL}$ for $24 \mathrm{~h}$, MTT assay was used to evaluate the cell viability. The results in Figure S5 demonstrated that $\mathrm{CuFeSe}_{2}$-PEG-FA had good biocompatibility, and no serious cytotoxicity toward 4T1 and HepG2 cells was observed in the range of $0-200 \mu \mathrm{g} / \mathrm{mL}$, in which the cell viability was higher than $80 \%$.

\section{In Vitro Targeted Assessment}

After 4T1 and HepG2 cells were incubated for 6 hours with the DMEM solution of $\mathrm{CuFeSe}_{2}$-PEG-FA and $\mathrm{CuFeSe}_{2}$ nanoparticles, we found that more targeted nanoparticles could bind to FA receptor on the surfaces of these cells compared with the control and untargeted groups (Figure S6A-E). Besides, 4T1 cells bound to more $\mathrm{CuFeSe}_{2}$-PEG-FA nanoparticles due to FA receptor overexpression compared with HepG2 cells (Figure $\underline{\mathrm{S} 6 \mathrm{C}}$ and $\underline{\mathrm{D}})$. However, in the untargeted group, both cells only bound to a few $\mathrm{CuFeSe}_{2}$ nanoparticles and no significant difference was found between two cells (Figure S6E and F). These results confirmed that $\mathrm{CuFeSe}_{2}$-PEG-FA nanoparticles had excellent targeted capability.

Furthermore, another related test also verified the successful modification of FA further. As is shown in Figure

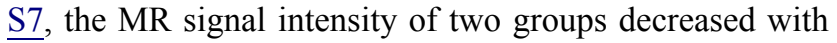
the increase of the concentration of the $\mathrm{CuFeSe}_{2}$-PEG-FA nanoparticles due to the dose-dependence of cellular

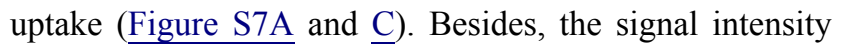
of A group was lower than that of B group and MR signal intensity was significantly different between two groups at the concentrations of $100 \mathrm{ug} / \mathrm{mL}(p=0.047)$ and $200 \mathrm{ug} /$ $\mathrm{mL}(p=0.049)$. Moreover, CT showed us that $\mathrm{CT}$ values of two groups increased with the increase of the concentration of the $\mathrm{CuFeSe}_{2}$-PEG-FA nanoparticles and $\mathrm{CT}$ values of $\mathrm{A}$ group were higher than that of $\mathrm{B}$ group (Figure S6B and D). Importantly, CT values had also a significant difference between two groups at the concentrations of $100 \mathrm{ug} / \mathrm{mL}(p=0.035)$ and $200 \mathrm{ug} / \mathrm{mL}(p=$ 0.009 ). What this suggests is that $4 \mathrm{~T} 1$ cells without experiencing a blocking assay can bind to more $\mathrm{CuFeSe}_{2}$-PEGFA nanoparticles compared with the control group, which verifies the successful modification of FA. 


\section{Toxicity Assessment In Vivo}

No death occurred and no abnormal activity was found in the mice within $15 \mathrm{~d}$ after they were injected with the $\mathrm{CuFeSe}_{2}$-PEG-FA nanoparticles via the tail vein. For these mice, H\&E staining indicated the microstructures of various organs including myocardial striation and muscle fibers, hepatic lobules and the hepatocytes, lymphoid follicles and germinal center, alveoli, collecting ducts and thigh muscle fibers, all exhibited normal morphology and were arranged regularly at different time points. No tissue necrosis and inflammatory response were observed compared with the control group (Figure 5).

\section{CT/MRI Dual-Modality Imaging of Cancer Cells In Vitro}

To confirm the cancer cell targeting ability of the $\mathrm{CuFeSe}_{2}$ PEG-FA nanoparticles and validate their $\mathrm{CT}$ and MRI performance, 4T1 (FAR overexpression) ${ }^{31}$ and HepG2 cells (Less FAR expression) ${ }^{32}$ were treated with the $\mathrm{CuFeSe}_{2}-$
PEG-FA nanoparticles at $37{ }^{\circ} \mathrm{C}$ and $5 \% \mathrm{CO}_{2}$ for 6 h. Then, CT imaging and T2WI of the cells were performed. From the T2WI and CT images of 4T1 cells treated with the $\mathrm{CuFeSe}_{2}$-PEG-FA nanoparticles (Figure S8), MR signal intensity decreased (Figure S8A and $\underline{\mathrm{C}}$ ), and $\mathrm{CT}$ value (Figure S8b, 8d) increased compared with that of 4T1 cells treated with the $\mathrm{CuFeSe}_{2}$ nanoparticles and glucose solution. What this suggests was that $\mathrm{CuFeSe}_{2}$-PEG-FA nanoparticles may be an appropriate positive control agent for enhanced CT imaging and a negative agent for T2WI.

In contrast, from the T2WI and CT images of HepG2 cells, there was no obvious change for both MR signal intensity, and CT values between the targeted and untargeted nanoparticles due to the less expression of FAR on the surface of HepG2 cells (Figure S8A and B). For 4T1 and HepG2 cells treated with the $\mathrm{CuFeSe}_{2}$-PEG-FA nanoparticles, the former had lower MR signal intensity $(p=0.008)$, higher CT value $(p=0.035)$ and their differences were statistically significant between two cells. This further

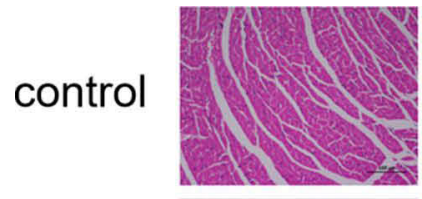

1 day

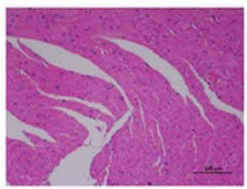

3 day

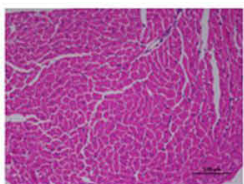

5 day
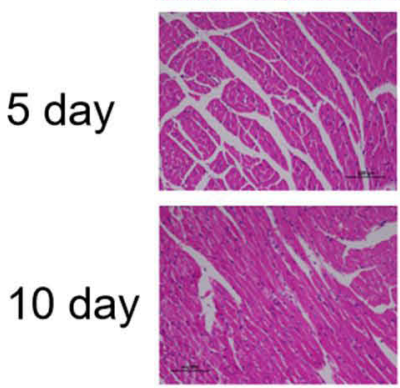

15 day

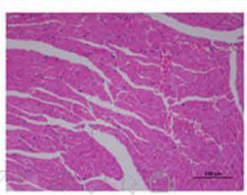

Heart
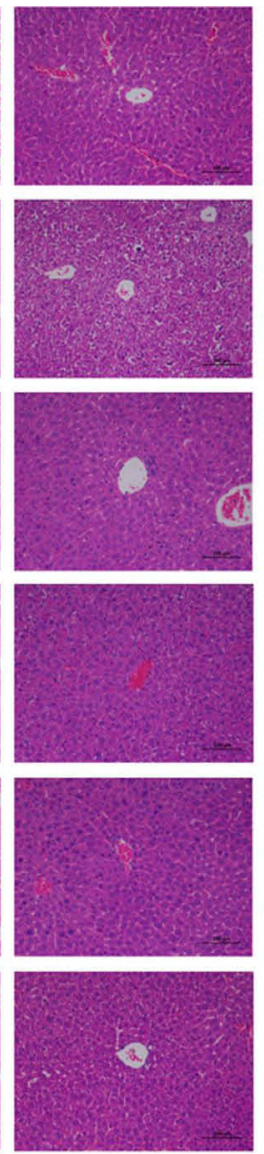

Liver
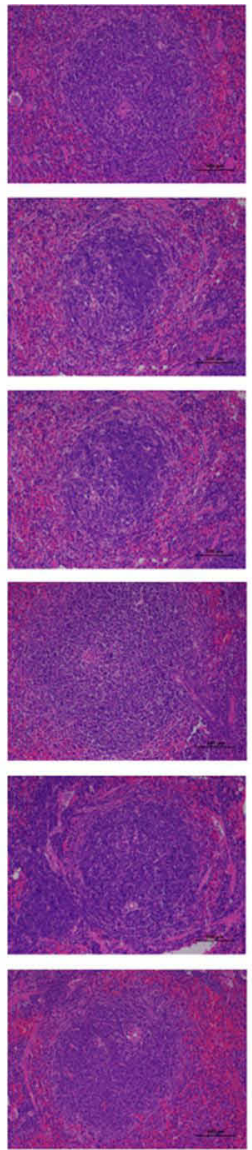

Spleen
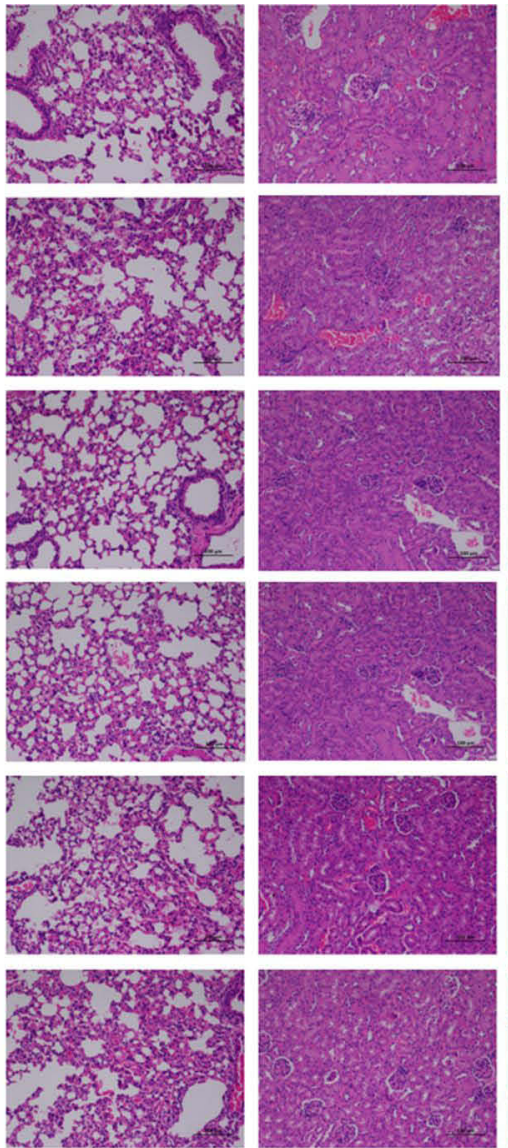

Lung

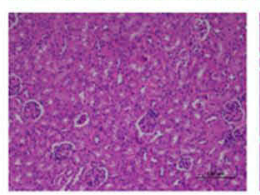

Kidney
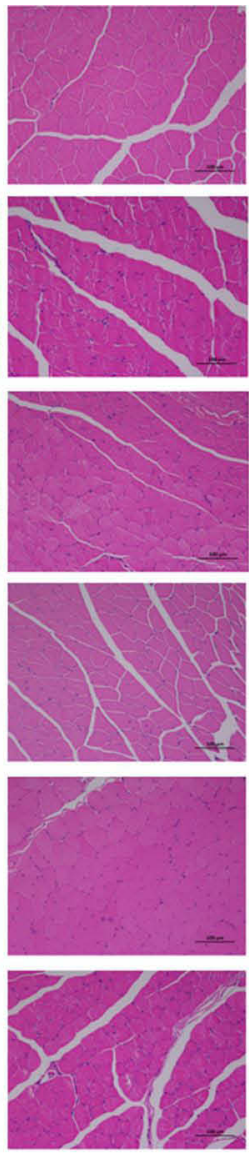

Muscle

Figure 5 Hematoxylin and eosin (H\&E) staining of important organs for normal mice at different time points after the injection of CuFeSe - -PEG-FA contrast agent and $5 \%$ glucose solution via the tail vein. 
illustrated the role played by the attached FA ligands that were able to direct an active targeting to 4T1 cells overexpressing FAR via a receptor-mediated pathway.

\section{CT/MRI Dual-Modality Imaging In Vivo}

First, we explored the feasibility of using $\mathrm{CuFeSe}_{2}$-PEG-FA nanoparticles for specific MRI of tumors in vivo (Figure 6) and the same dosage of $\mathrm{CuFeSe}_{2}$ and $5 \%$ glucose solution were used as a control. Figure $6 \mathrm{~A}$ showed the fusion images of T2WI and T2* map for 4T1 tumor model obtained before injection, and $2 \mathrm{~min}, 30 \mathrm{~min}, 1 \mathrm{~h}, 5 \mathrm{~h}$ and $12 \mathrm{~h}$ post-injection, respectively. It could be seen that the tumor MR signal of mice injected with $\mathrm{CuFeSe}_{2}$-PEG-FA nanoparticles gradually decreased as a function of time (the range from $0-5 \mathrm{~h}$ ) and subsequently gradually increased (Figure 6A). Besides, a significant difference was found between $\mathrm{T} 2 *$ values of tumor tissue before injection and that at the time points of 5 $\mathrm{h}$ and $8 \mathrm{~h}$ post-injection $(p<0.05)$ (Table 1$)$. However, no significant difference was found between $\mathrm{T} 2 *$ values of tumor tissue before and after injection in liver and muscle tissue $(p>$ 0.05 ) (Tables S1 and $\underline{\mathrm{S} 2}$ ). The above results demonstrated that the targeted $\mathrm{CuFeSe}_{2}$-PEG-FA nanoparticles had a great potential to be a negative control agent for T2WI.

For the untargeted group, it could be observed that the tumor MR signal had a similar trend with the targeted group (Figure 6B). However, there was no significant difference between $\mathrm{T} 2 *$ values of tumor tissue before and after injection. In sharp contrast, the tumor MR signal of mice treated with 5\% glucose solution increased first and then decreased gradually (Figure 6C). No significant difference was found between $\mathrm{T} 2 *$ value of tumor tissue before and after injection, which indicated that $5 \%$ glucose solution could not reduce $\mathrm{T} 2 *$ value of tumor tissue. In addition, T2* value was significantly different for the experimental $(21.42 \pm 2.79)$ and control group $(32.35 \pm 4.21)(p<0.01)$, which further confirmed that the $\mathrm{CuFeSe}_{2}$-PEG-FA nanoparticles could

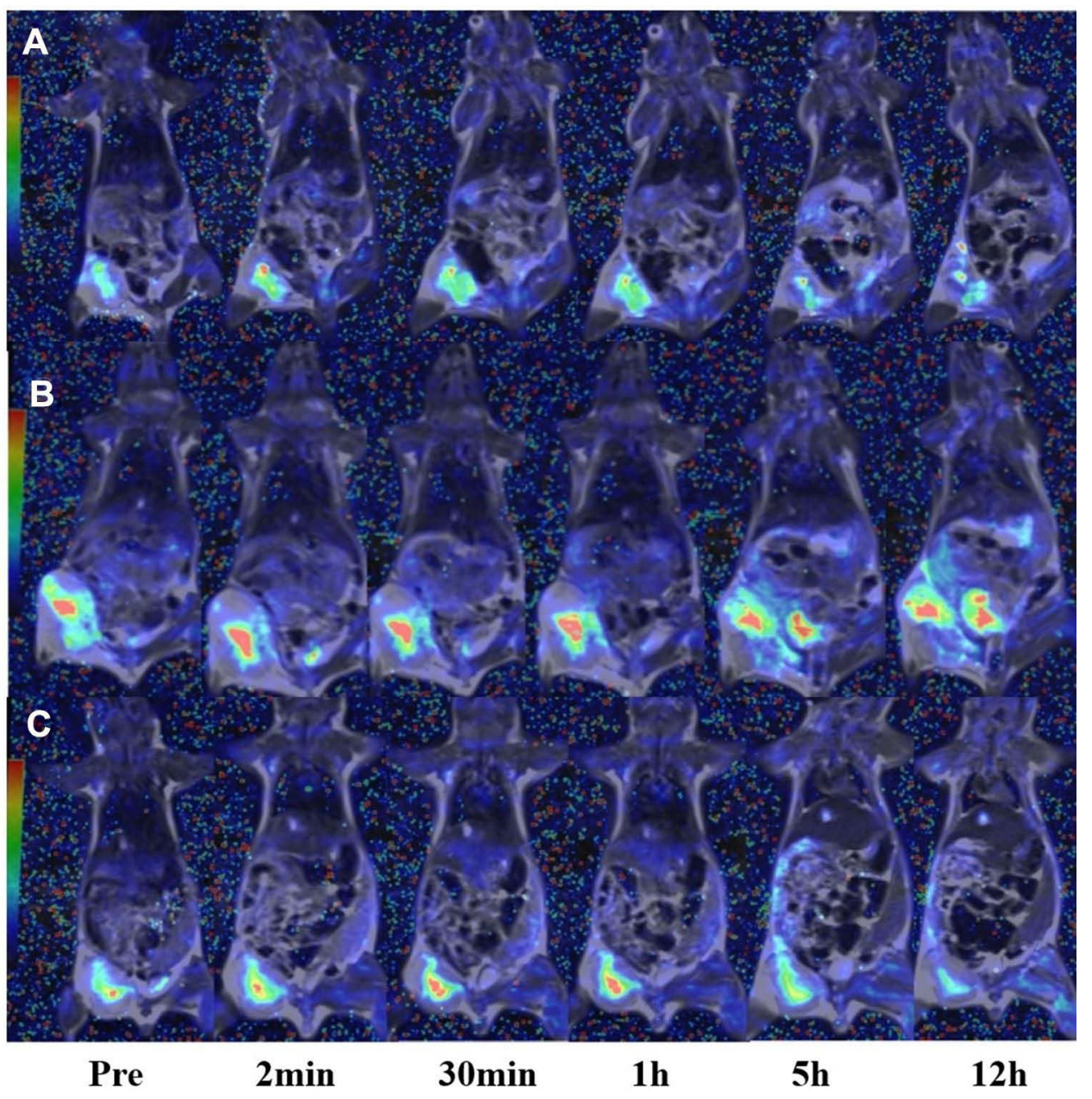

Figure 6 The fusion images of T2WI and T2* map for 4TI tumor model, acquired at 0, $2 \mathrm{~min}, 30 \mathrm{~min}, \mathrm{I} \mathrm{h,} 5 \mathrm{~h}$ and $\mathrm{I} 2 \mathrm{~h}$ after the mice were intravenously injected with the $\mathrm{CuFeSe}_{2}$-PEG-FA nanoparticles (A), CuFeSe 2 nanoparticles (B) and $5 \%$ glucose solution (C) respectively. 
Table I The T2* Value of Tumor at Different Time Points Before and After the Injection

\begin{tabular}{|c|c|c|c|c|c|c|}
\hline $\begin{array}{l}\text { Scanning } \\
\text { Time }\end{array}$ & $\begin{array}{l}\text { The T2* Value of Tumor in } \\
\text { Experiment Group }(n=3)\end{array}$ & $p$ & $\begin{array}{c}\text { The T2* Value of Tumor in } \\
\text { Control Group }(n=2)\end{array}$ & $p$ & $\begin{array}{l}\text { The T2* Value of Tumor in } \\
\text { Untargeted Group }(n=2)\end{array}$ & $p$ \\
\hline Pre & $28.20 \pm 4.27$ & & $30.88 \pm 12.18$ & & $28.38 \pm 6.12$ & \\
\hline $2 \min$ & $22.30 \pm 4.19$ & 0.138 & $32.66 \pm 6.50$ & 0.734 & $27.04 \pm 4.37$ & 0.729 \\
\hline $30 \mathrm{~min}$ & $22.16 \pm 3.56$ & 0.302 & $31.12 \pm 10.20$ & 0.892 & $28.28 \pm 3.93$ & 0.979 \\
\hline $\mathrm{I} \mathrm{h}$ & $22.31 \pm 0.27$ & 0.126 & $37.61 \pm 1.30$ & 0.542 & $27.85 \pm 4.70$ & 0.853 \\
\hline $1.5 \mathrm{~h}$ & $22.19 \pm 1.32$ & 0.155 & $37.51 \pm 2.60$ & 0.507 & $24.61 \pm 2.67$ & $0.27 I$ \\
\hline $2 \mathrm{~h}$ & $16.99 \pm 5.18$ & 0.052 & $31.53 \pm 4.95$ & 0.919 & $24.21 \pm 3.89$ & 0.329 \\
\hline $3 \mathrm{~h}$ & $21.58 \pm 3.19$ & 0.190 & $36.04 \pm 6.96$ & 0.395 & $24.53 \pm 3.52$ & 0.182 \\
\hline $4 \mathrm{~h}$ & $21.49 \pm 4.26$ & 0.223 & $34.70 \pm 8.58$ & 0.375 & $24.11 \pm 3.21$ & 0.159 \\
\hline $5 \mathrm{~h}$ & $18.14 \pm 1.00$ & 0.040 & $35.07 \pm 4.36$ & 0.587 & $22.12 \pm 3.08$ & 0.072 \\
\hline $6 \mathrm{~h}$ & $21.41 \pm 4.79$ & 0.261 & $31.03 \pm 4.29$ & 0.983 & $22.67 \pm 1.39$ & 0.186 \\
\hline $8 \mathrm{~h}$ & $21.48 \pm 2.08$ & 0.045 & $24.48 \pm 1.40$ & 0.555 & $23.15 \pm 2.98$ & 0.263 \\
\hline $12 \mathrm{~h}$ & $18.82 \pm 3.87$ & 0.099 & $25.59 \pm 0.22$ & 0.644 & $23.77 \pm 3.82$ & 0.291 \\
\hline
\end{tabular}

Note: The T2* values of tumor before and after the injection were expressed as mean \pm SD.

reduce the $\mathrm{T} 2 *$ value of tumor tissue after excluding the interference of $5 \%$ glucose solution.

ICP results displayed that Fe element content of tumor tissue in the experimental group $(33.40 \pm 1.78 \mathrm{mg} / \mathrm{kg})$ was higher than that in the untargeted $(28.53 \pm 1.21 \mathrm{mg} / \mathrm{kg})$ and control group $(26.30 \pm 1.70 \mathrm{mg} / \mathrm{kg})$ and there existed a significant difference between the pairwise $(p<0.05)$ (Figure S9). What this suggested was that $\mathrm{CuFeSe}_{2}$-PEGFA nanoparticles could reduce the $\mathrm{T} 2 *$ value by increasing Fe content of tumor tissue.

For the CT imaging of intravenous injection, we could see that the average CT values of tumor tissue after administration of the $\mathrm{CuFeSe}_{2}$-PEG-FA nanoparticles were higher than those before injection (Figure 7). Table S3 showed that there was a significant difference between $\mathrm{CT}$ values before and after injection (at the time points of $8 \mathrm{~h}$ and $12 \mathrm{~h}$ postinjection, $p<0.05)$. Hence, the $\mathrm{CuFeSe}_{2}$-PEG-FA nanoparticles had the power to raise CT values of tumor tissue at larger concentrations and may serve as an excellent CT contrast agent for various biomedical applications.

\section{Conclusion}

In summary, a facile approach has been developed to generate multifunctional $\mathrm{CuFeSe}_{2}$-PEG-FA nanoparticles for CT/MRI dual-modality targeted imaging. The formed multifunctional $\mathrm{CuFeSe}_{2}$-PEG-FA nanoparticles exhibited outstanding water solubility, cytocompatibility, hemocompatibility, and biosafety in the given concentration range. With the targeting specificity to cancer cells overexpressing FAR being confirmed, the developed $\mathrm{CuFeSe}_{2}$-PEG-FA nanoparticles were able to be used as an efficient nanoprobe for CT/MRI dualmodality imaging of cancer cells in vitro and a xenografted tumor model in vivo via a FA-mediated

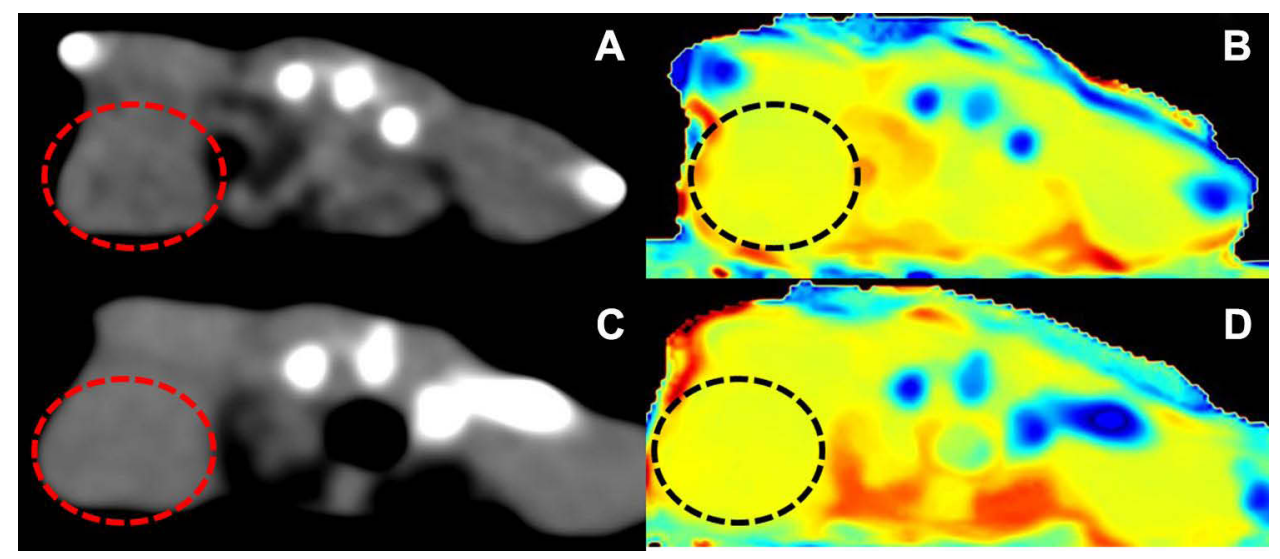

Figure $7(\mathbf{A})$ and $(\mathbf{C})$ are conventional CT images before and after intravenous injection respectively. (B) and (D) are effective atomic number images before and after intravenous injection respectively. The red and black circles represent the tumor tissues. 
active targeting pathway. Our results suggested that this nanoparticle may appear as an attractive candidate for a future theranostic platform.

\section{Abbreviations}

CT, computed tomography; MRI, magnetic resonance imaging; FA-PEG-COOH, folate-conjugated polyethylene glycol; FA, folic acid; FAR, FA receptors; $\mathrm{NaBH}_{4}$, sodium borohydride; APTES, 3-aminopropyltriethoxysilan; DMF, dimethylformamide; EDCI, N-(3-dime thylaminopropyl)-N'-ethylcarbodiimide hydrochloride; NHS, N-hydroxysuccinimide; RPMI-1640, Roswell Park Memorial Institute-1640; DMEM, dulbecco's minimum essential medium; FBS, fetal bovine serum; DMSO, dimethyl sulfoxide; TEM, transmission Electron microscope; XRD, X-ray powder diffractometer; ICP-OES, inductively coupled plasma optical emission spectrometry; FTIR, Fourier transform infrared spectrometer; FOV, field of view; T2WI, T2 weighted imaging; TR, repetition time; TE, echo time; MTT, 3-(4,5-dimethylthiazol-2-yl)2,5-diphenyltetrazolium bromide; HRTEM, high resolution transmission electron microscopy; SAED, selected area electron diffraction; EDX, energy dispersive X-ray spectroscopy.

\section{Acknowledgments}

The authors are grateful for the support from the NSFC (81903460), the Open Program of Nuclear Medicine and Molecular Imaging Key Laboratory of Sichuan Province (HYX19004), the Technology Strategic Cooperation Project between Luzhou Municipal People's Government and Southwest Medical University (2020LZXNYDJ42), the Project of Southwest Medical University (2018ZRZD008, 2020ZRQNA041) and the Project of the Affiliated Hospital of Southwest Medical University (18107).

\section{Author Contributions}

All authors contributed to data analysis, drafting or revising the article, have agreed on the journal to which the article will be submitted, gave final approval of the version to be published, and agree to be accountable for all aspects of the work.

\section{Disclosure}

The authors report no conflicts of interest in this work.

\section{References}

1. de Vries A, Custers E, Lub J, et al. Block-copolymer-stabilized iodinated emulsions for use as CT contrast agents. Biomaterials. 2010;31(25):6537-6544. doi:10.1016/j.biomaterials.2010.04.056

2. Schwenzer NF, Springer F, Schraml C, et al. Non-invasive assessment and quantification of liver steatosis by ultrasound, computed tomography and magnetic resonance. $J$ Hepatol. 2009;51 (3):433-445. doi:10.1016/j.jhep.2009.05.023

3. Jiang X, Zhang $\mathrm{S}$, Ren F, et al. Ultrasmall magnetic $\mathrm{CuFeSe}_{2}$ ternary nanocrystals for multimodal imaging guided photothermal therapy of cancer. ACS Nano. 2017;11(6):5633-5645. doi:10.1021/acsnano.7b 01032

4. Tian S, Liu G, Wang X, et al. pH-Responsive tumor-targetable theranostic nanovectors based on core crosslinked (CCL) micelles with fluorescence and magnetic resonance (MR) dual imaging modalities and drug delivery performance. Polymers. 2016;8(6):226. doi:10.3390/polym8060226

5. Oh MH, Lee N, Kim H, et al. Large-scale synthesis of bioinert tantalum oxide nanoparticles for X-ray computed tomography imaging and bimodal image-guided sentinel lymph node mapping. $J \mathrm{Am}$ Chem Soc. 2011;133(14):5508-5515. doi:10.1021/ja200120k

6. Yang $\mathrm{H}$, Zhuang $\mathrm{Y}, \mathrm{Hu} \mathrm{H}$, et al. Silica-coated manganese oxide nanoparticles as a platform for targeted magnetic resonance and fluorescence imaging of cancer cells. Adv Funct Mater. 2010;20 (11):1733-1741. doi:10.1002/adfm.200902445

7. Estelrich J, Sánchez-Martín MJ, Busquets MA. Nanoparticles in magnetic resonance imaging: from simple to dual contrast agents. Int J Nanomedicine. 2015;10:1727-1741. doi:10.2147/IJN.S76501

8. Li L, Wu C, Pan L, et al. Bombesin-functionalized superparamagnetic iron oxide nanoparticles for dual-modality MR/NIRFI in mouse models of breast cancer. Int J Nanomedicine. 2019;14:6721-6732. doi:10.2147/IJN.S211476

9. Ni D, Zhang J, Bu W, et al. PEGylated $\mathrm{NaHoF}_{4}$ nanoparticles as contrast agents for both X-ray computed tomography and ultra-high field magnetic resonance imaging. Biomaterials. 2016;76:218-225. doi:10.1016/j.biomaterials.2015.10.063

10. Hallouard F, Anton N, Choquet P, et al. Iodinated blood pool contrast media for preclinical X-ray imaging applications-a review. Biomaterials. 2010;31:6249-6268. doi:10.1016/j.biomaterials.20 10.04 .066

11. Mattrey RF, Aguirre DA. Advances in contrast media research. Acad Radiol. 2003;10(12):1450-1460. doi:10.1016/s1076-6332(03) 00642-1

12. Maynard RL. Nano-technology and nano-toxicology. Emerg Health Threats J. 2012;5:245-260. doi:10.3402/ehtj.v5i0.17508.

13. Branca M, Pelletier F, Cottin B, et al. Design of FeBi nanoparticles for imaging applications. Faraday Discuss. 2014;175:97-111. doi:10.1039/c4fd00105b

14. Cai H, Li K, Li J, et al. Dendrimer-assisted formation of $\mathrm{Fe}_{3} \mathrm{O}_{4} / \mathrm{Au}$ nanocomposite particles for targeted dual mode CT/MR imaging of tumors. Small. 2015;11(35):4584-4593. doi:10.1002/smll.201500856

15. Liang S, Zhou Q, Wang M, et al. Water-soluble L-cysteine-coated FePt nanoparticles as dual MRI/CT imaging contrast agent for glioma. Int J Nanomedicine. 2015;10:2325-2333. doi:10.2147/IJN. S75174

16. Wen S, Li K, Cai H, et al. Multifunctional dendrimer-entrapped gold nanoparticles for dual mode CT/MR imaging applications. Biomaterials. 2013;34(5):1570-1580. doi:10.1016/j.biomaterials.20 12.11.010

17. Lee N, Cho HR, Oh MH, et al. Multifunctional $\mathrm{Fe}_{3} \mathrm{O}_{4} / \mathrm{TaO}(\mathrm{x})$ core/ shell nanoparticles for simultaneous magnetic resonance imaging and X-ray computed tomography. $J$ Am Chem Soc. 2012;134 (25):10309-10312. doi:10.1021/ja3016582 
18. Carril M, Fernandez I, Rodriguez J, et al. Gold-coated iron oxide glyconanoparticles for MRI, CT, and US multimodal imaging. Part Part Syst Charact. 2014;31(1):81-87. doi:10.1002/ppsc.201300239

19. Yin $\mathrm{Q}$, Jin $\mathrm{X}$, Yang $\mathrm{G}$, et al. Biocompatible folate-modified $\mathrm{Gd}^{3+} / \mathrm{Yb}^{3}$ ${ }^{+}$-doped $\mathrm{ZnO}$ nanoparticles for dualmodal MRI/CT imaging. Rsc Adv. 2014;4(96):53561-53569. doi:10.1039/c4ra08100e

20. Jiang $\mathrm{X}$, Han Y, Zhang $\mathrm{H}$, et al. Cu-Fe-Se ternary nanosheet-based drug delivery carrier for multimodal imaging and combined chemo/ phot othermal therapy of cancer. ACS Appl Mater Interfaces. 2018;10 (50):43396-43404. doi:10.1021/acsami.8b15064

21. Wu M, Fu S, Shu J, et al. Amphiphilic polymer-modified uniform $\mathrm{CuFeSe}_{2}$ nanoparticles for CT/MR dual-modal imaging. Contrast Media Mol Imaging. 2020;2020:4891325. doi:10.1155/2020/4891325

22. Wang W, Jiang J, Ding T, et al. Alternative synthesis of $\mathrm{CuFeSe}_{2}$ nanocrystals with magnetic and photoelectric properties. ACS Appl Mater Interfaces. 2015;7(4):2235-2241. doi:10.1021/am508844w

23. Lai L-Y, Jiang Y, Su G-P, et al. Gadolinium-chelate functionalized magnetic $\mathrm{CuFeSe}_{2}$ ternary nanocrystals for T1-T2 dual MRI and CT imaging in vitro and in vivo. Mater Res Express. 2021;8(4):045001. doi:10.1088/2053-1591/abfla2

24. Campbell IG, Jones TA, Foulkes WD, et al. Folate-binding protein is a marker for ovarian cancer. Cancer Res. 1991;51:5329-5338.

25. Ross JF, Chaudhuri PK, Ratnam M. Differential regulation of folate receptor isoforms in normal and malignant tissues in vivo and in established cell lines - Physiologic and clinical implications. Cancer. 1994;73(9):2432-2443. doi:10.1002/1097-0142(19940501)73:9<243 $2:$ aid-cncr2820730929>3.0.co; 2 -s
26. Weitman SD, Lark RH, Coney LR, et al. Distribution of the folate receptor GP38 in normal and malignant cell lines and tissues. Cancer Res. 1992;52:3396-4301.

27. Li L, Gao F, Jiang W, et al. Folic acid-conjugated superparamagnetic iron oxide nanoparticles for tumor-targeting MR imaging. Drug Deliv. 2016;23:1726-1733. doi:10.3109/10717544.2015.1006404

28. Yu W, Yu N, Wang Z, et al. Chitosan-mediated green synthesis and folic-acid modification of $\mathrm{CuS}$ quantum dots for photoacoustic i maging guided photothermal therapy of tumor. J Colloid Interface Sci. 2019;555:480-488. doi:10.1016/j.jcis.2019.08.001

29. Qiao J, Dong P, Mu X, et al. Folic acid-conjugated fluorescent polymer for up-regulation folate receptor expression study via targ eted imaging of tumor cells. Biosens Bioelectron. 2016;78:147-153. doi:10.1016/j.bios.2015.11.021

30. Li J, Zheng L, Cai H, et al. Polyethyleneimine-mediated synthesis of folic acid-targeted iron oxide nanoparticles for in vivo tumor MR imaging. Biomaterials. 2013;34(33):8382-8392. doi:10.1016/j. biomaterials.2013.07.070

31. Chen Y, Tezcan O, Li D, et al. Overcoming multidrug resistance using folate receptor-targeted and $\mathrm{pH}$-responsive polymeric nanogels containing covalently entrapped doxorubicin. Nanoscale. 2017;9 (29):10404-10419. doi:10.1039/c7nr03592f

32. Aranda C, Urbiola K, Mendez Ardoy A, et al. Targeted gene delivery by new folate-polycationic amphiphilic cyclodextrin-DNA nanocomplexes in vitro and in vivo. Eur J Pharm Biopharm. 2013;85 (3):390-397. doi:10.1016/j.ejpb.2013.06.011
International Journal of Nanomedicine

\section{Publish your work in this journal}

The International Journal of Nanomedicine is an international, peerreviewed journal focusing on the application of nanotechnology in diagnostics, therapeutics, and drug delivery systems throughout the biomedical field. This journal is indexed on PubMed Central, MedLine, CAS, SciSearch ${ }^{\circledR}$, Current Contents ${ }^{\mathbb{R}} /$ Clinical Medicine, $^{-}$

\section{Dovepress}

Journal Citation Reports/Science Edition, EMBase, Scopus and the Elsevier Bibliographic databases. The manuscript management system is completely online and includes a very quick and fair peer-review system, which is all easy to use. Visit http://www.dovepress.com/ testimonials.php to read real quotes from published authors. 